\title{
Cystic Schwannoma Arising from Supraorbital Nerve Masquerading as a Dermoid: An Unusual Case
}

\author{
Kanishk Singh $^{1 *}$, Ankur Shrivastava ${ }^{2}$ and Amrita Singh ${ }^{3}$ \\ ${ }^{1}$ Assistant Professor, Ophthalmology Department, All India Institute of Medical \\ Sciences (AIIMS, Nagpur), India \\ ${ }^{2}$ Associate Professor, Ophthalmology Department, All India Institute of Medical \\ Sciences (AIIMS, Raipur), India \\ ${ }^{3}$ Assistant Professor, Obstetrics and Gynaecology Department (NKP Salve \\ Institute of Medical Sciences, Nagpur), India \\ *Corresponding Author: Kanishk Singh, Assistant Professor, Ophthalmology \\ Department, All India Institute of Medical Sciences (AIIMS, Nagpur), India.
}

Received: October 11, 2020

Published: October 28, 2020

(C) All rights are reserved by Kanishk Singh., et al.

\begin{abstract}
We are presenting a rare case of Cystic Schwannoma which was masquerading as a dermoid.The patient was 23 year old male presented with a slow growing mass over his right supero-medial side of the orbit since last two and a half years. Examination showed a solid, non-tender, freely mobile mass of around $15 \times 15 \mathrm{~mm}$ in the supero-nasal orbit, which was firm to hard in consistency, nonpulsatile, non-reducible in nature. CT scan of right orbit revealed a well-defined hypo attenuated skin based lesion in the right supraorbital region which measures $11.9 \times 14.6 \times 15.2 \mathrm{~mm}(\mathrm{AP} \times \mathrm{TRA} \times \mathrm{CC})$. A complete tumour resection was performed, and pathologic examination showed it as a case schwannoma of orbit. Schwannomas are infrequent tumours which arise from the orbit coming behind Inflammatory, vascular and lymphoproliferative diseases; treatment is complete resection of the mass with subsequent monitoring to prevent recurrence.
\end{abstract}

Keywords: Cystic Schwannoma; Supraorbital Nerve Masquerading; Dermoid

\section{Introduction}

Schwannomas are benign tumors of peripheral nerve sheath which account for around $1-6 \%$ of all orbital tumors. These tumors are localised, well encapsulated and mostly unilateral which are composed of proliferating Schwann cells [1]. They are mostly unilateral which may arise from supraorbital, infraorbital, supratrochlear, ciliary, oculomotor, trochlear or abducens nerves. They may spread along any cranial or peripheral nerve. Amongst which the eigth cranial nerve is the commonest site [2,3]. Orbital schwannoma is a tumor of adulthood usually presenting between 20 to 70 years of age. It has been found that schwannomas mostly arise from branches of either the supraorbital or supratrochlear nerves thus produce downward displacement of the globe [4]. The tumor may also arise from the infraorbital nerve and produce upward displacement of globe which is not so common. Depending upon the variable location and origin of these orbital tumors, a variable combination of signs and symptoms can be seen. Schwannoma with cystic degeneration is an even more rarely reported entity [5].

\section{Case Report}

A 23 year old male presented with a slow growing mass over his right supero-medial side of the orbit at the level of his eye brow since last two and a half years. The mass was gradually increasing in size and was not associated with any pain or any painful ocular movement. There was no complaint of diminution of vision or diplopia. On examination the visual acuity of both eyes was 20/20 unaided. A solid, non-tender, freely mobile mass of around $15 \times 15$ $\mathrm{mm}$ in the supero-nasal orbit was seen (Figure 1). It was firm to 
hard in consistency, nonpulsatile, nonreducible, and freely mobile in nature. There was no globe displacement or proptosis and the ocular motility was full and painless in all directions. Anterior segment was normal with intact corneal sensation and fundus was normal. On further evaluation pupillary reaction, color vision and visual fields were also within normal limit. CT scan of right orbit revealed a well-defined hypo attenuated skin based lesion in the right supraorbital region which measures $11.9 \times 14.6 \times 15.2 \mathrm{~mm}$ $($ AP $\times$ TRA $\times$ CC) (Figure 2). A provisional diagnosis of orbital dermoid was made and the patient was taken up for an excision biopsy. Systemic and hematological evaluation was done and surgery was planned under local anesthesia. A complete in toto surgical excision of tumor was done as shown (Figure 3), with careful separation and preservation of nerve from which it was arising. As supraorbital notch was found beneath the mass which suggested that tumor was originated from supraorbital nerve. Postoperative period was uneventful. Histopathological examination (Figure 4), reveals a single grayish white globular soft tissue mass measuring $1.5 \mathrm{~cm}$ in diameter showing classically a biphasic pattern, designated Antoni A and B cells in varying proportion suggestive of schwannoma with cystic degeneration.

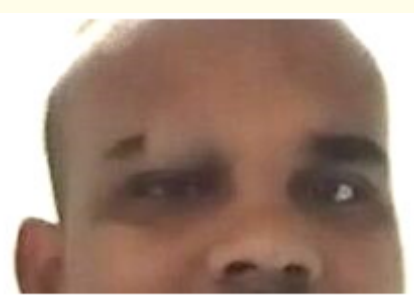

Figure 1: Schwannoma presenting as cystic lesion over right supero-medial side of the orbit at the level eyebrow.

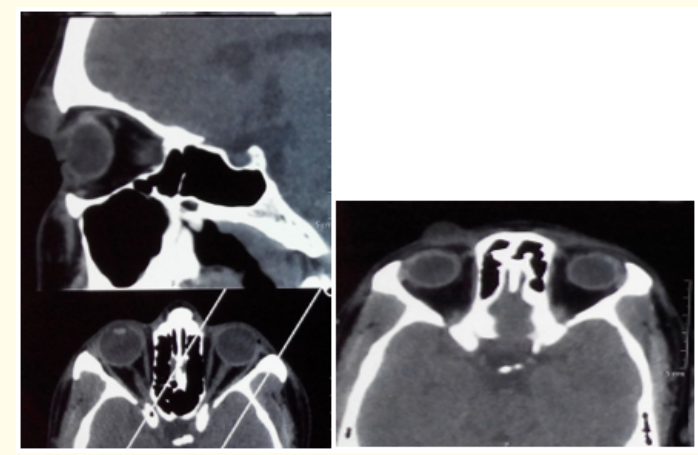

Figure 2: Preoperative radiological features on CT scan showing the mass in the right Superior orbit.

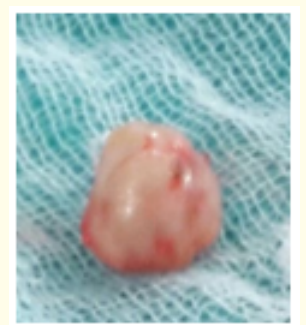

Figure 3: Gross appearance of excised mass.

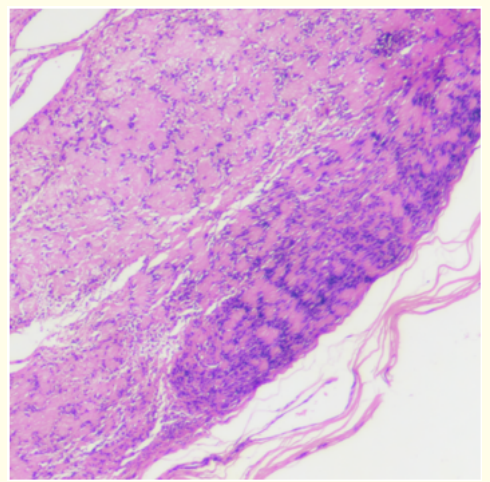

Figure 4: Benign schwannoma showing classically a biphasic pattern, designated Antoni A and B cells is present in varying proportion.

\section{Discussion}

Schwannomas of orbit are one of the rare tumors and they are also seen in association with neurofibromatosis in around $2 \%$ $18 \%$ of the cases [6]. These tumors are usually encapsulated and non invasive in nature and has minimum effect on orbital structure $[7,8]$. Sometimes orbital schwannoma can affect the eye by mechanical compression which can cause globe displacement, diplopia and proptosis [9-11]. Study conducted by Singh M., et al. found that $69 \%$ of the orbital schwannoma were unilateral with preponderance for the right orbit [12], which correlates with our report. Garg R., et al. and Dulani S., et al. found that these orbital tumors were slow growing in nature and was not associated with any pain, globe displacement, ocular immobility or dimension of vision, which was also seen in our case report [4,6]. However, Subramanian N., et al. found proptosis and decreased in vision in their four cases of orbital schwannoma with cystic degeneration as these tumors present as intraconal mass in the orbit [5]. In all these cases complete excision of mass was performed and histopathology re- 
port confirm the diagnosis. Orbital tumors are rare in origin and have always posed diagnostic challenges to an ophthalmologist, tumors of neurogenic origin are even rare and account for around $1 \%$ of all orbital tumor [13-15]. The differential diagnosis of an orbital mass consist of aneurysmal bone cyst, neurofibroma, dermoid cyst, hemangioma, schwannoma should be included in the differential diagnosis of cystic orbital lesions [16]. Orbital schwannomas are usually asymptomatic till they are small, it can be associated with proptosis and pain on enlargement sometimes clinical presentation of the mass near the orbital apex can cause retro-orbital neuritis. Apart from that pressure can also leads to conditions such as papilledema and optic nerve atrophy $[13,17]$. In the present case no such manifestation and complications was seen. Henceforth early diagnosis and treatment are indicated to avoid the complications related to progressive growth of the tumor.

\section{Conclusion}

Orbit schwannoma is one of a rare tumor, it is difficult to differentiate these benign masses from other orbital tumours on radiologic imaging. A definitive diagnosis can be made through correlation with histopathologic findings. The standard treatment protocol is surgery-based, with complete excision of the mass. Schwannomas have a low malignant potential with rare recurrence. However, the approach towards this tumor can vary accordingly with the location of the tumor, depending from orbital anatomical side which need to be individualized.

\section{Conflicts of Interest}

There is no conflicts of interest.

\section{Bibliography}

1. Gorgan R., et al. "A rare type of tumor: orbital schwannoma. Case report and literature review". Romanian Neurosurgery 30.1 (2016): 47-51.

2. Nair A., et al. "Epibulbar schwannoma in a 12-year-old boy: A case report and review of literature". Indian Journal of Ophthalmology 63.7 (2015): 620-622.

3. Grover AK., et al. "Schwannoma of the orbit". Indian Journal of Ophthalmology 41.3 (1993): 128-129.

4. Garg R., et al. "A rare case of benign isolated schwannoma in the inferior orbit". Indian Journal of Ophthalmology 56.6 (2008): 514-515.

5. Subramanian N., et al. "Cystic Schwannoma of the Orbit-A Case Series". Orbit Journal 24.2 (2005): 125-129.

6. Dulani S., et al. "A Bilobed Schwannoma in Roof of Orbit: A Rare Case Report". Case Reports in Ophthalmological Medicine 10 (2012): 1-4.
7. Rootman J., et al. "Primary orbital schwannomas". British Journal Of Ophthalmology 66 (1982): 194-204.

8. Kron M., et al. "Recurrent orbital schwannomas: Clinical course and histopathologic correlation". BMC Ophthalmology 12.44 (2012): 1-3.

9. Izumo T., et al. "Intraorbital schwannoma arising from the supraorbital nerve”. No Shinkei Geka 40.2 (2012): 167-171.

10. Kauser H., et al. "Orbital oculomotor nerve schwannoma extending to the cavernous sinus: a rare cause of proptosis". Journal of Ophthalmic and Vision Research 9.4 (2014): 514516.

11. Ghosh S., et al. "Orbital extension of trigeminal schwannoma". Journal of Neurosciences in Rural Practice 6.1 (2015): 102-104.

12. Singh M., et al. "Clinico-Radiological Spectrum and Management of Orbital Schwannomas: A Tertiary Care Institute Study". Orbit 32.3 (2013): 171-177.

13. Hemalatha AL., et al. "Rare retro-orbital intraconal occurrence of benign schwannoma - a case report". Journal of Clinical and Diagnostic Research 7.12 (2013): 2964-2965.

14. Khetan VD. "Giant subperiosteal orbital Schwannoma with luxated globe". Journal of Ophthalmology and Clinical Research 1 (2013): 159-162.

15. Kinger A., et al. "Plexiform schwannoma of infraorbital nerve - A rare case report". International Journal of Biomathematics 2.3 (2013).

16. Search for reff.

17. Brucoli M., et al. "A benign isolated schwannoma of the orbit". Journal of Craniofacial Surgery 22.6 (2011): 2372-2374.

\section{Assets from publication with us}

- Prompt Acknowledgement after receiving the article

- Thorough Double blinded peer review

- Rapid Publication

- Issue of Publication Certificate

- High visibility of your Published work

Website: www.actascientific.com/

Submit Article: www.actascientific.com/submission.php Email us: editor@actascientific.com

Contact us: +919182824667 